\title{
Genetic Predisposition for Type 2 Diabetes Mellitus in a Cameroonian Population: Contribution of rs4731702 (C/T) Polymorphism of Krüppel-Like Factor 14 Gene
}

\author{
Magellan Guewo-Fokeng1,2, Eugene Sobngwi ${ }^{2,3,4}$, Barbara Atogho-Tiedeu 2,5, \\ Eric Lontchi-Yimagou ${ }^{2,5}$, Jean-Paul Chedjou ${ }^{2,5}$, Jean-Claude Mbanyaa, ${ }^{2,3,4}$, Wilfred F. Mbacham ${ }^{1,2 *}$ \\ ${ }^{1}$ Department of Biochemistry, Faculty of Medicine and Biomedical Sciences, University of Yaoundé I, Yaoundé, Cameroon \\ ${ }^{2}$ The Biotechnology Centre, University of Yaoundé I, Nkolbisson, Yaoundé, Cameroon \\ ${ }^{3}$ Department of Internal Medicine and Specialties, Faculty of Medicine and Biomedical Sciences, University of Yaoundé I, \\ Yaoundé, Cameroon \\ ${ }^{4}$ National Obesity Center, Diabetes, Endocrinology and Metabolic Diseases, Yaoundé Central Hospital, Yaoundé, Cameroon \\ ${ }^{5}$ Department of Biochemistry, Faculty of Science, University of Yaoundé I, Yaoundé, Cameroon \\ Email: *wfmbacham@yahoo.com, sobngwieugene@yahoo.fr, guewomagellan@yahoo.fr
}

How to cite this paper: Guewo-Fokeng, M., Sobngwi, E., Atogho-Tiedeu, B., Lontchi-Yimagou, E., Chedjou, J.-P., Mbanya, J.-C. and Mbacham, W.F. (2021) Genetic Predisposition for Type 2 Diabetes Mellitus in a Cameroonian Population: Contribution of rs4731702 (C/T) Polymorphism of Krüppel-Like Factor 14 Gene. Open Journal of Genetics, 11, 9-22. https://doi.org/10.4236/ojgen.2021.112002

Received: February 21, 2021

Accepted: April 6, 2021

Published: May 27, 2021

Copyright $\odot 2021$ by author(s) and Scientific Research Publishing Inc. This work is licensed under the Creative Commons Attribution International License (CC BY 4.0).

http://creativecommons.org/licenses/by/4.0/ (c) (i) Open Access

\begin{abstract}
Introduction: Krüppel Like Factor 14 (KLF14) gene has recently been identified as a master gene for multiple metabolic phenotypes. The aim of the research study was to investigate the relationship between KLF14 rs4731702 $(\mathrm{C} / \mathrm{T})$ gene polymorphism with Type 2 Diabetes Mellitus (T2DM) in a Cameroonian population. Patients and Methods: This case-control study was conducted in 85 patients with T2DM and 95 healthy normoglycemic controls. All were nonrelated, of Cameroonian origin, and were adults aged 24 years old and above. Demographic, clinical and biological data were collected, and biochemical explorations were performed using enzymatic colorimetric methods. The genotyping of KLF14 rs4731702 (CT) gene polymorphism was done by the Polymerase Chain Reaction and Restriction Fragment Length Polymorphism. Results: In comparing the Cameroonian population that consisted of 85 patients with T2DM and 95 healthy controls, the minor or risk allele of the rs4731702 (C/T) polymorphism of the KLF14 gene was T $(63.53 \%$ diabetic patients vs. $26.32 \%$ healthy controls, $\mathrm{OR}=4.877$ and $\mathrm{p}<0.0001$ ) while the protective allele was C (36.47\% diabetic patients vs. $73.68 \%$ healthy controls, $\mathrm{OR}=0.205$ and $\mathrm{p}<0.0001$ ). The susceptibility to T2DM was higher among subjects having the CT and TT genotypes with $\mathrm{OR}=2.721$ and $\mathrm{p}=$ $0.0145)$ and $\mathrm{OR}=3.907$ and $\mathrm{p}<0.0001)$ respectively. This gene polymorphism was not preferentially associated with a specific diabetes phenotype.
\end{abstract}


Conclusion: This study has demonstrated for the first time the relationship between the KLF14 rs4731702 (C/T) gene polymorphism and T2DM in this Cameroonian population. This gene polymorphism could be a promising target for personalized medicine through the development of clinical genetic testing.

\section{Keywords}

Genetic, Krüppel-Like Factor 14 Gene, Type 2 Diabetes Mellitus, Cameroon

\section{Introduction}

Type 2 Diabetes Mellitus (T2DM) is a polygenic metabolic disease, the most common form (more than 90\%) is that in which insulin resistance and deficiency lead to high blood glucose levels due to the fact that in this state, the body produces insulin but becomes resistant to it so that it is ineffective [1]. In 2019, there were more than 350 million adult persons at high risk of developing diabetes, in the same year, 463 million adults had diabetes and by 2045 this number is projected to get to 700 million. In this period of time, sub-Saharan Africa will experience a 143\% increase from 19 million in 2019 to 47 million in 2045. It remains one of the major public health problems with an increase in social and economic burdens in both low-income and high-income countries [2].

$\mathrm{T} 2 \mathrm{DM}$ is a complex multifactorial disease. Including toxins, stress, diet, obesity, sedentary lifestyle, small or large birth weight and physical inactivity as environmental factors and many genetic variants or loci that have been proven to be associated or conferring risk to T2DM or contribute to the individual differences in the susceptibility or predisposition to this disease. The identification of these variants has followed three main waves, from family-based linkage studies, while passing through candidate gene analysis, Genome Wide Association Study (GWAS) and then large-scale studies of association between certain DNA sequence variants in different ethnic groups [3], more than 60 susceptibility gene mutations for T2DM have been described. Their numbers started increasing in 2007 with the first GWAS which by replication in other populations in the world improved the capacity for researchers to discover positions and gene polymorphisms implicated in the susceptibility of metabolic disease phenotypes [4]-[9]. In Africa, only two GWAS conducted to date on the Africa America Diabetes Mellitus [10] [11]. Yako and collaborators showed that until June 2014 only, 100 polymorphisms including SNP, indels, and repeats in 57 genes were investigated, with the majority of studies carry out on the white populations from Northern African countries, principally Tunisia and Egypt. The genetic risk factors revealed by their meta-analysis represent the most promising T2DM risk genes identified and described to date in Africans [12].

Focused on these ten genes, TPMT (Thiopurine S-methyltransferase), ARSD (Arylsulfatase D), SLC7A10 (Solute carrier family 7 neutral amino acid trans- 
porter light chain, a system, member 10, C8orf82 (Chromosome 8 open reading frame 82), APH1B (APH1B gamma secretase subunit), PRMT2 (Protein arginine methyltransferase 2), NINJ2 (Ninjurin 2), KLF13 (Kruppel-like factor 13), GNB1 (Guanine nucleotide binding protein, beta polypeptide 1), MYL5 (Myosin, light chain 5, regulatory) with Trans associations driven by $\mathrm{rs} 4731702(\mathrm{C} / \mathrm{T})$ polymorphism, the Krüppel Like Factor 14 (KLF14) gene (intronless member of the KLF family located at chromosome 7q32) [13] has been identified as a master switch gene and trans-regulatory to multiple metabolic phenotypes including T2DM [14]. This transcription factor family, of which 17 have been identified in mammalian systems, is characterized by three highly conserved (Cys2/His2-type) and homologous C-terminal zinc finger domains. These domains are implicated in regulation by DNA binding through the activation and/or repression of the transcription of many genes with roles in diverse biological processes that include responses to external stress, growth, proliferation, differentiation, development and survival due to their variable N-terminal domain [15] [16]. In addition to this exciting discovery, in a Cameroonian population, studies on the PPAR- $\gamma 2$ Pro12Ala gene polymorphism [17] and the TCF7L2 rs12255372 (G/T), rs7903146 (C/T) gene polymorphisms [17] [18] showed that TCF7L2 rs7903146 gene polymorphism is strongly associated with T2DM, but contrary to other populations, the T allele was not associated with $\mathrm{T} 2 \mathrm{DM}$; it rather had a protective effect [19]. For these reasons, it is therefore important to study and understand the implication of the KLF14 rs4731702 (C/T) gene polymorphism in the predisposition to T2DM among Cameroonians. This will help to provide valuable insight on the genetic factors of T2DM, and thus contribute to the creation of a large database and the idea of personalized medicine.

\section{Methods}

\subsection{Study Participants}

This was a case-control study involving 85 T2DM Patients and 95 controls of Cameroonian origin, aged 24 and over. Patients with T2DM (with glutamic acid decarboxylase (GAD) antibody negativity) were enrolled in the study at the National Center for Obesity at the Yaoundé Central Hospital and normoglycemic controls (with no personal or family history of diabetes) with fasting plasma glucose level less than $1.1 \mathrm{~g} / \mathrm{L}$ from the general population after providing detailed information on the objectives and procedures of the study. Physical examination was conducted with data collection on sex, age and clinical parameters were collected for all participants. Height, waist circumference and hip circumference to the nearest $0.5 \mathrm{~cm}$, and weight to the nearest $0.1 \mathrm{~kg}$, were measured. The Body Mass Index (BMI) and the Waist-to-Hip Ratio (WHR) were defined according to the International Diabetes Foundation (IDF) criteria. Blood pressure was the mean of two measurements performed at least three minutes apart on the right arm, with the subject seated after a 15 min rest, using an automatic Omron HEM-705 CP sphygmomanometer recorder $\left(\mathrm{OMRON}^{\circledR}\right.$ MX2 
Basic, OMRON HEALTHCARE, INC. Bannockburn, Illinois 60015.CHINA) with standardized procedures. The percentage of fat mass was measured using bioimpedance (TANITA ${ }^{\circledR}$ BC 420 MA, TANITA Corporation 1-14-2 Maeno-cho, Tabashi-ku, Tokyo Japan). Diagnosis of T2DM was based on a history of doctor-diagnosis that was conducted according to the American Diabetes Association (ADA) and World Health Organization (WHO) definitions [20] [21]: FPG concentration $\geq 7.0 \mathrm{mmol} / \mathrm{L}$ (or $\geq 126 \mathrm{mg} / \mathrm{dL}$ ) and/or 2-hour post-Oral Glucose Tolerance Test (OGTT) plasma glucose $\geq 11.1 \mathrm{mmol} / \mathrm{L}$ (or $\geq 200 \mathrm{mg} / \mathrm{dL}$ ). Alternatively, this was accepted if an individual was on pharmacological treatment for T2DM and a review of medical records indicated adequate justification for that therapy. Added to this, the detection of autoantibodies to GAD antibody was used to exclude probable cases of type 1 diabetes. Glycated haemoglobin (HbA1c) was measured by High Performance Liquid Chromatography (HPLC) with an Automated Biochemistry Analyzer Bio-Rad in2it TM (I). The Homeostatic Model Assessment Insulin Resistance (HOMA-IR) and functional $\beta$-cells (HOMA-B) were estimated using the formula: HOMA-IR $=$ [fasting insulin concentration $(\mathrm{mU} / \mathrm{L}) \times \mathrm{FPG}(\mathrm{mmol} / \mathrm{L}] / 22.5$ ] [22] (with Insulin resistance defined by any value of the HOMA-IR index equal to or above 2.1) [23] and $0.27 \times$ fasting C-peptide $(\mu \mathrm{U} / \mathrm{ml}) /$ fasting glucose $(\mathrm{mmol} / \mathrm{ml})-3.5$ respectively [22].

\subsection{Sample Preparation}

Two venous blood samples were aseptically collected in EDTA and plain tubes in the morning following an overnight fasting for at least 12 hours. They were kept on ice $\left(4^{\circ} \mathrm{C}\right)$ and immediately transported to the laboratory where serum specimen was separated accordingly from the plain tube sample by centrifuging for 5 minutes at $3000 \mathrm{rpm}$. The extraction of genomic DNA was done from the dried blood stains on the Whatmann filter paper (from EDTA tube sample) by the Chelex method [24] and stored at $-20^{\circ} \mathrm{C}$ for further analysis.

\subsection{Biochemical Assays}

FPG levels were measured by the glucose oxidase-peroxidase method using an automatic portable Life Scan OneTouch Ultra glucometer (Johnson \& Johnson, USA). Total cholesterol (TC) (cholesterol oxidase phenol-4-amino antipyrene peroxidase method, derived from that described by Allain and collaborators) [25], serum triglycerides (TG) (glycerol phosphatase oxidase-phenol4-amino antipyrene peroxidase method, derived from that described by Buccolo and Davids) [26], and high-density lipoprotein (HDL)-cholesterol (cholesterol oxidase phenol-4-amino antipyrene peroxidase method, in the supernatant, derived from that described by Burstein and collaborators) [27] were measured by standardized enzymatic methods on a spectrophotometer (UV Mini 1240) using Chronolab kits. The Friedwald formula was used to calculate Low-density lipoprotein (LDL)-cholesterol concentrations, when TG levels were below $4 \mathrm{mmol} / \mathrm{L}$, and measured when TG values were over $4 \mathrm{mmol} / \mathrm{L}$ [28]. Dyslipidemia was considered as an elevated level of TC $(>6.2 \mathrm{mmol} / \mathrm{L})$ and/or an elevated level of 
LDL-cholesterol ( $>4.1 \mathrm{mmol} / \mathrm{L})$ and/or a low HDL-cholesterol level $(<1.04 \mathrm{mmol} / \mathrm{L}$ in men and $1.29 \mathrm{mmol} / \mathrm{L}$ in women) and/or an elevated level of TG ( $\geq 1.7 \mathrm{mmol} / \mathrm{L})$ [29].

\subsection{DNA Extraction, Amplification and Molecular Genotyping}

Genomic DNA was extracted from filter paper stained with whole blood by the Chelex method. One hundred and eighty (180) participants (85 type 2 diabetic patients and 95 healthy controls) were genotyped for KLF14 rs4731702 (C/T) by PCR-RFLP. The KLF14 rs4731702 (C/T) polymorphism was genotyped using its corresponding number and size of appearing bands. PCR was performed with these Forward primer 5'-AATCCCAAGGCATCTATC-3' and Reverse primer 5'-CTTGGATTTTGATTACGG-3' (SIGMA-ALDRICH, United States). For the amplification, each $25 \mu \mathrm{L}$ PCR reaction mixture consisted of $3 \mu \mathrm{L}$ of genomic DNA, $0.25 \mu \mathrm{L}$ of each primer (10 pmol/L), $12.5 \mu \mathrm{L}$ of Go Taq Green PCR Master Mix (20 mM Tris-HCl, pH 8.3; 100 mM KCl; 3 mM MgCl2; 0.1 U Taq polymerase/ $\mu \mathrm{L} ; 500 \mu \mathrm{M}$ dNTP each QIAGEN) and $9 \mu \mathrm{L}$ of ddH2O (DNase/RNase-free). The PCR was carried out under the following conditions: initial denaturation at $94^{\circ} \mathrm{C}$ for 5 minutes, followed by 35 cycles of denaturation at $94^{\circ} \mathrm{C}$ for 45 seconds, primer annealing at $53^{\circ} \mathrm{C}$ for 45 seconds, primer extension at $72^{\circ} \mathrm{C}$ for 45 seconds and a final extension at $72^{\circ} \mathrm{C}$ for 7 minutes. The amplicons were analyzed by agarose gel electrophoresis using a $2 \%$ agarose gel and $6 \mu \mathrm{L}$ of positive amplification products ( $347 \mathrm{bp}$ ) digested with $5 \mathrm{U}$ of Bacillus stearothermophilus I (BsrI) restriction enzyme at $65^{\circ} \mathrm{C}$ overnight. Agarose gels (3\%) stained with ethidium bromide were used to separate the digested amplicons which were then visualized under a UV lamp transilluminator. This restriction enzyme digestion produced three (3) bands of different sizes: a 347 bp corresponding to the TT genotype (restriction site absent); a set of $133 \mathrm{bp}$ and $214 \mathrm{bp}$ corresponding to the CC genotype (restriction site present) and a set of $133 \mathrm{bp}, 214 \mathrm{bp}$ and $347 \mathrm{bp}$ corresponding to CT genotype (restriction site present and absent). To ensure that the genotyping was of good quality, all gels were reread blindly by another person without any change and random duplicates were performed in about $10 \%$ of the samples in each genotyping assay. No genotype errors were detected in the random duplicates.

\subsection{Sample Size Calculation}

This was performed prior to the initiation of the study. A sample size of 80 T2DM patients and 80 healthy controls was required to detect the polymorphism with an effect size of 1.5 for significance threshold of 0.05 and an expected allele frequency of 0.10 in the general population, with statistical power of $80 \%$ ( $\alpha=0.05$ and $\beta=0.20$ ) at this locus. The Quanto statistical software was used to calculate the power and Sample size [30].

\subsection{Data Management and Statistical Analyses}

Participant data obtained were entered into a log book, and later keyed into a 
computer using the 2016 version of Microsoft excel sheets and verified for the possibility of entering errors. Genotype and allele distributions in patients with T2DM and healthy controls were obtained by direct counting. Qualitative variables were analyzed by the Chi square $\left(\chi^{2}\right)$ test or Fisher's exact test. Quantitative variables were compared using non-parametric tests (Mann Whitney or Kruskall Wallis with post hoc multiple comparison by Dunn-Sidak test) and described using median and inter quartile domain (IQR, 25th-75th percentiles) or mean \pm standard deviation $(M \pm S D)$, and categorical variables using their frequency and percentage. The genotype frequencies were tested for the Hardy-Weinberg equilibrium using a $\chi^{2}$ test. Odd Ratios (OR) with $95 \%$ confidence intervals (CI), were calculated using unconditional logistic regression. Data were coded, entered and analyzed using the Statistical Package for Social Sciences (SPSS) version 20.0 for Windows (Chicago, Illinois, USA) and were considered as statistically significant when $\mathrm{p}<0.05$.

\section{Results}

\subsection{Characteristics of the Study Population}

The characteristics of the studied population are presented in Table 1. There were no significant difference distributions between diabetic patients and normoglycemic controls for gender (male/female ratio 0.89 vs. $0.73 ; \mathrm{p}=0.5494$ ), age

Table 1. Characteristics of the study population.

\begin{tabular}{|c|c|c|c|}
\hline Parameters & $\begin{array}{c}\text { Type } 2 \text { diabetic patients } \\
\mathrm{n}=85\end{array}$ & $\begin{array}{l}\text { Healthy controls } \\
\qquad \mathrm{n}=95\end{array}$ & $P$ value \\
\hline \multicolumn{4}{|l|}{ Demographic } \\
\hline Male/female (ratio) & $40 / 45(0.89)$ & $40 / 55(0.73)$ & 0.5494 \\
\hline Age (years) & $50.00(44.00-56.00)$ & $49.00(42.00-53.00)$ & 0.1599 \\
\hline \multicolumn{4}{|l|}{ Clinical } \\
\hline $\mathrm{BMI}\left(\mathrm{Kg} / \mathrm{m}^{2}\right)$ & $27.56(24.03-30.68)$ & $27.51(23.03-31.57)$ & 0.8042 \\
\hline WHR & $0.90(0.85-1.00)$ & $0.85(0.08-0.90)$ & $<0.0001$ \\
\hline Fat Mass \% & $26.90(19.40-33.60)$ & $31.93(23.18-40.93)$ & 0.0336 \\
\hline $\mathrm{SBP}(\mathrm{mmHg})$ & $126.0(113.0-142.0)$ & $127.0(118.0-150.0)$ & 0.1762 \\
\hline DBP (mmHg) & $80.00(73.00-88.50)$ & $79.00(71.00-90.00)$ & 0.9657 \\
\hline \multicolumn{4}{|l|}{ Biochemical } \\
\hline FPG $(g / L)$ & $3.44(2.59-4.38)$ & $0.92(0.85-1.01)$ & $<0.0001$ \\
\hline $\mathrm{TC}(\mathrm{g} / \mathrm{L})$ & $4.13(2.93-5.30)$ & $1.83(1.67-2.06)$ & $<0.0001$ \\
\hline $\mathrm{TG}(\mathrm{g} / \mathrm{L})$ & $1.25(1.08-1.85)$ & $1.39(1.26-1.60)$ & 0.1373 \\
\hline HDL-C (g/L) & $0.83(0.54-1.17)$ & $0.49(0.45-0.54)$ & $<0.0001$ \\
\hline LDL-C (g/L) & $2.42(1.29-3.45)$ & $1.05(0.89-1.26)$ & $<0.0001$ \\
\hline AI(LDL-C/HDL-C) & $2.58(1.85-3.93)$ & $2.13(1.84-2.82)$ & 0.0166 \\
\hline
\end{tabular}

Notes: Data are medians (interquartile range) unless otherwise stated. Abbreviations: BMI, Body Mass Index; WHR, Waist to Hip Ratio; SBP, Systolic Blood Pressure; DBP, Diastolic Blood Pressure; FPG, Fasting Plasma Glucose; TC, Total Cholesterol; TG, Triglycerides; HDL-C, High Density Lipoprotein cholesterol; LDL-C, Low Density Lipoprotein Cholesterol; AI, Atherogenic Index = LDL cholesterol/HDL-cholesterol. 
(median age 50.00 years vs. 49.00; $\mathrm{p}=0.1599$ ) and BMI (median age 27.56 years vs. 27.51; $\mathrm{p}=0.8042$ ). On the contrary, for WHR (median value 0.90 vs. $0.85 ; \mathrm{p}<$ 0.001), FPG (median level 3.44 vs. 0.92; p < 0.0001), TC (median level 4.13 vs. 1.83 ; $\mathrm{p}<0.0001$ ), HDL-C (median level 0.83 vs. 0.49; $\mathrm{p}<0.0001$ ) and LDL-C (median level 2.42 vs. $1.05 ; \mathrm{p}<0.0001$ ), the same significant difference distributions were observed between diabetic patients and normoglycemic controls respectively. HbA1c (median value 8.6\%), HOMA (median value 9.04) and $\beta$-cell functions (median value 0.01 ) were assessed only for diabetic patients.

\subsection{Frequency of KLF14 rs4731702 (C/T) Gene Polymorphism}

All T2DM patients and normoglycemic controls were positively genotyped for the KLF14 rs4731702(C/T) gene polymorphism. After amplification characterized on agarose gel by one band of 347 bp (Figure 1), the genotyping was characterized on agarose gel by two bands of $214 \mathrm{bp}$ and $133 \mathrm{bp}$ for the wild type homozygote CC, one band of $347 \mathrm{bp}$ for the mutant homozygote TT, and three bands of $347 \mathrm{pb}, 214 \mathrm{pb}$ and $133 \mathrm{bp}$ for the mutant heterozygote CT (Figure 2).

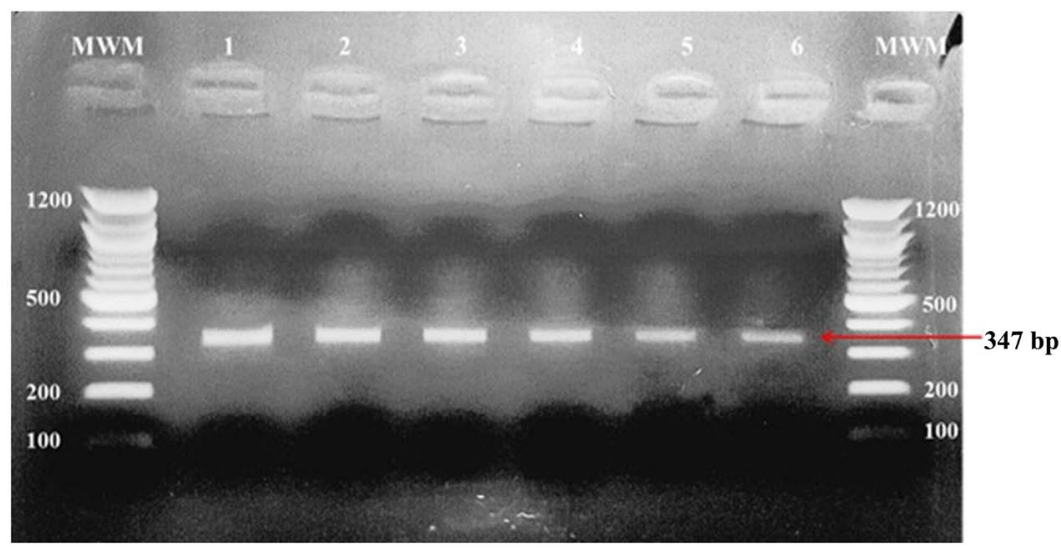

Figure 1. Electrophoresis of PCR products of the KLF14 rs4731702 (C/T) gene polymorphism. Notes: Lane MWM, 100 bp Molecular Weight Marker; lanes 1 - 6, PCR products (347 bp).

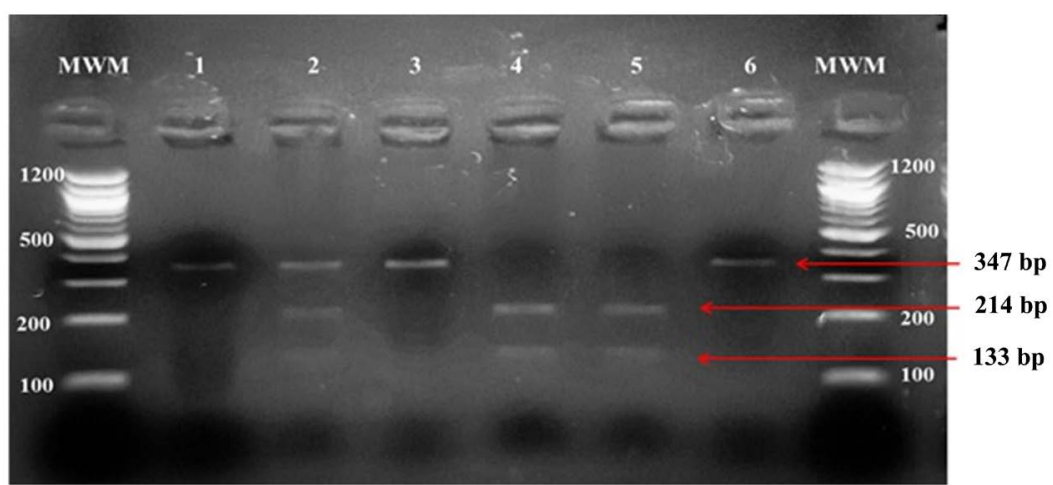

Figure 2. Electrophoresis of digested PCR products for the genotyping of the KLF14 rs4731702 (C/T) gene polymorphism. Notes: Lane MWM, 100 bp Molecular Weight Marker; lanes 1, 3 and 6, TT genotype (347 bp); lanes 2, CT genotype (347 bp, 214 bp, and $133 \mathrm{bp}$ ); lanes 4 and 5, CC genotype (214 bp and $133 \mathrm{bp}$ ). 
In the general population, the frequency of the CC genotype was $46.11 \%$ (83/180), vs. $20.00 \%(36 / 180)$ and $33.89 \%(61 / 180)$ for the CT and the TT genotypes respectively.

\subsection{Genetic Variants and Type 2 Diabetes Mellitus}

This matching population was not in Hardy-Weinberg equilibrium $\left(\chi^{2}=34.76\right.$; $\mathrm{p}$ $<0.0001)$. The $\mathrm{C}$ allele was major with a frequency of $56.11 \%$, as compared to the minor $\mathrm{T}$ allele which showed a frequency of $43.89 \%$.

The KLF14 rs4731702 (C/T) gene polymorphism was strongly associated with T2DM, with OR $=4.877(95 \% \mathrm{CI}[3.112-7.644]$ and $\mathrm{p}<0.0001)$ for the $\mathrm{T}$ allele and $\mathrm{OR}=2.721(95 \% \mathrm{CI}[1.263-5.865]$ and $\mathrm{p}=0.0145), \mathrm{OR}=3.907(95 \% \mathrm{CI}$ [2.022 - 7.549] and $\mathrm{p}<0.0001)$ for the CT and TT genotypes respectively. The T allele (minor) was demonstrated to be the risk allele (63.53\% diabetic patients vs. $26.32 \%$ healthy controls, $\mathrm{OR}=4.877$ and $\mathrm{p}<0.0001$ ) while the $\mathrm{C}$ allele was demonstrated to be the protective allele (36.47\% diabetic patients vs. $73.68 \%$ healthy controls, $\mathrm{OR}=0.205$ and $\mathrm{p}<0.0001$ ). The CC genotype was protective (22.35\% diabetic patients vs. $67.37 \%$ healthy controls, $\mathrm{OR}=0.139$ and $\mathrm{p}<$ 0.0001 ) against the disease (Table 2).

\subsection{Correlation between Genetic Variants and Diabetic Traits}

According to the rs4731702 (C/T) genotypes, the genotype-phenotype correlations were performed. The clinical (BMI, WHR, SBP, DBP and Fat Mass percentage) and biochemical (FPG, TC, LDL-C, HDL-C, TG, AI (LDL-C/HDL-C), HbAlc (\%), HOMA- $\beta$ (Pep-C) and HOMA-IR) characteristics of the total population were stratified (Table 3 ). The median FPG was significantly different ( $\mathrm{p}$ $<0.0001$ ) in the three (CC, CT and TT) genotype groups with the higher values in the individuals presenting the CT genotype. The medians concentrations of TC $(\mathrm{p}<0.0001)$, HDL-C $(\mathrm{p}=0.0004)$ and LDL-C $(\mathrm{p}<0.0001)$ were significantly

Table 2. Case-control association analysis of KLF14 rs4731702(C/T) with T2DM.

\begin{tabular}{cccccc}
\hline $\begin{array}{c}\text { KLF14 rs4731702 } \\
(\mathrm{C} / \mathrm{T})\end{array}$ & $\begin{array}{c}\text { Type 2 diabetic } \\
\text { patients }\end{array}$ & $\begin{array}{c}\text { Healthy } \\
\text { controls }\end{array}$ & OR & CI 95\% & p value \\
\hline $\begin{array}{c}\text { Alleles } \\
\text { C }\end{array}$ & $62(36.47)$ & $140(73.68)$ & 0.205 & $0.131-0.321$ & $<0.0001$ \\
T & $108(63.53)$ & $50(26.32)$ & 4.877 & $3.112-7.644$ & $<0.0001$ \\
Total (2n) & $170(100)$ & $190(100)$ & & & \\
Genotypes & & & & & \\
CC & $19(22.35)$ & $64(67.37)$ & 0.139 & $0.072-0.272$ & $<0.0001$ \\
CT & $24(28.24)$ & $12(12.63)$ & 2.721 & $1.263-5.865$ & 0.0145 \\
TT & $42(49.41)$ & $19(20.00)$ & 3.907 & $2.022-7.549$ & $<0.0001$ \\
Total (n) & $85(100)$ & $95(100)$ & & & \\
\hline
\end{tabular}

Notes: The results are given as n (\%). Abbreviations: KLF14, Kruppel Like Factor 14; OR, Odds Ratio; CI, Confidence Interval. 
Table 3. Genotype and allele frequency distribution for KLF14 rs4731702 variant and the clinical and biochemical characteristics.

\begin{tabular}{ccccc}
\hline \multirow{2}{*}{ Characteristics } & CC & Genotypes & P value \\
\cline { 2 - 5 } Clinical & & $\mathrm{CT}$ & $\mathrm{TT}$ & \\
\hline BMI $\left(\mathrm{Kg} / \mathrm{m}^{2}\right)$ & $27.84(23.41-32.07)$ & $26.02(23.47-28.56)$ & $27.85(24.01-32.34)$ & 0.3263 \\
WHR & $0.90(0.80-0.90)$ & $0.90(0.85-0.99)$ & $0.90(0.85-1.00)$ & 0.1117 \\
Fat Mass \% & $30.50(22.04-39.34)$ & $28.37(22.65-32.94)$ & $27.80(19.63-36.43)$ & 0.6777 \\
SBP (mmHg) & $128(118.00-152.00)$ & $127(108.50-142.80)$ & $126(114.50-139.50)$ & 0.5097 \\
DBP (mmHg) & $80.00(71.00-93.00)$ & $78.50(73.25-88.00)$ & $80.00(71.00-88.50)$ & 0.8917 \\
Biochemical & & & & \\
FPG (g/L) & $0.98(0.88-1.16)$ & $2.72(0.99-4.145)$ & $2.63(0.99-3.86)$ & $<0.0001$ \\
TC (g/L) & $1.87(1.66-2.30)$ & $3.00(1.85-4.96)$ & $3.31(1.80-4.61)$ & $<0.0001$ \\
TG (g/L) & $1.39(1.20-1.61)$ & $1.43(1.22-1.73)$ & $1.27(1.16-1.58)$ & 0.3318 \\
HDL-C (g/L) & $0.50(0.465-0.59)$ & $0.64(0.47-0.93)$ & $0.67(0.49-1.15)$ & 0.0004 \\
LDL-C (g/L) & $1.07(0.84-1.50)$ & $1.76(1.04-3.23)$ & $1.79(1.03-2.70)$ & $<0.0001$ \\
AI (LDL-C/HDL-C) & $2.13(1.73-2.87)$ & $2.61(2.03-3.73)$ & $2.38(1.83-2.99)$ & 0.0584 \\
(a)HbA1c (\%) & $9.45(6.85-11.85)$ & $9.35(7.10-10.80)$ & $8.7(7.70-9.95)$ & 0.7077 \\
(a)HOMA- $\beta$ (Pep-C) & $0.01(0.005-0.02)$ & $0.01(0.005-0.02)$ & $0.01(0.001-0.019)$ & 0.8312 \\
(a)HOMA-IR & $13.15(6.19-19.06)$ & $8.37(5.83-13.83)$ & $8.87(3.24-16.24)$ & 0.3930 \\
\hline
\end{tabular}

Notes: Data are medians (interquartile range) unless otherwise stated. Abbreviations: BMI, Body Mass Index; WHR, Waist to Hip Ratio; SBP, Systolic Blood Pressure; DBP, Diastolic Blood Pressure; FPG, Fasting Plasma Glucose; TC, Total Cholesterol; TG, Triglycerides; HDL-C, High Density Lipoprotein cholesterol; LDL-C, Low Density Lipoprotein Cholesterol; AI, Atherogenic Index = LDL Cholesterol/HDL-cholesterol; HbA1C, glycated haemoglobin; HOMA-IR, Homeostasis Model Assessment of Insulin Resistance; HOMA- $\beta$, $\beta$-cell functions; (a), only for the 85 type 2 diabetic patients.

different with the higher values in the individuals presenting the TT genotype. As for the KLF14 rs4731702 (C/T) gene polymorphism, no significant genotype-phenotype characteristics were observed in the control group and also in a specific phenotype of T2DM (data not shown).

\section{Discussion}

T2DM, a complex metabolic disorder that may result in the interaction between genetical and environmental factors, is now one of the major public health problems worldwide. Despite the growing burden of the disease in sub-Saharan Africa and the efforts made by clinicians and fundamental researchers to prevent and halt the progression of the complications, its prevalence is on the rise in many low-income countries, and Cameroon is no exception. The participation of Africans in genomics research is very insignificant and therefore information on the genetic variants for T2DM in the continent are very scarce, leading to a poor understanding of the genetic part of the disease pathophysiology [12]. The present investigation presents the high implication of the rs4731702 (C/T) po- 
lymorphism of the KLF14 gene in the susceptibility to this disease in a Cameroonian population. Because of the genetic diversity between different ethnic groups, the frequency of the risk allele $\mathrm{T}$ in our population was found to be 43.89\% which, as reported by the HapMap data, was comparable to those observed in European (45.0\%), Chinese (36.7\%), Japanese (30.0\%) and Yoruba (23.3\%). This frequency was more important in in normal Icelanders (56.1\%) [31], and recently Huang and co-workers also found it to be $35.7 \%$ in Mulao and 33.4\% in Han [32]. The present study showed that this $\mathrm{T}$ allele was found to be strongly associated with the predisposition to T2DM with an OR of 4.877 (95\% CI $3.112-7.644, \mathrm{p}<0.0001$ ). This result is the first (except our previous study on this gene with the same Polymorphism in association with Ketosis-Prone Diabetes in a Cameroonian population [33]) to be provided on the susceptibility to T2DM, though Kerrin and co-workers in 2011 had demonstrated that the KLF14 gene acts as a master switch gene for the genes associated with T2DM and obesity. Their research suggested a trans-interaction between the expressions of the KLF14 gene and ten other genes implicated in a variety of metabolic disorders [14].

Recently, Gao and co-workers conducted an investigation on the association of the KLF14 gene with another SNP (rs972283) and find no association with T2DM in Han Chinese population of the Henan province [34], this was the first study on this gene in association with T2DM. In this Cameroonian population, we conducted the second study on this gene but not with the same polymorphism. In our total study population, the distribution of the CC genotype was $46.11 \%(83 / 180)$, vs. $20.00 \%(36 / 180)$ and $33.89 \%(61 / 180)$ for the CT and the TT genotypes respectively, showing that this population was deviated from Hardy-Weinberg equilibrium $\left(\chi^{2}=34.76\right.$; $\left.\mathrm{P}<0.0001\right)$ in the general population, probably due to the high frequency of homozygotes in our study population or to the impact of the rapid increase of T2DM in Cameroonian population [2]. This deviation was most probably due to our sample size as described in: "Testing for Hardy-Weinberg equilibrium in small samples" by Elston and Forthofer [35].

This KLF14 rs4731702 (C/T) gene variant was not preferentially associated with a specific disease phenotype but was related to the CC, CT and TT genotypes. The stratification of clinical and biochemical parameters showed that the FPG median was significantly different $(\mathrm{p}<0.0001)$ in the three $(\mathrm{CC}, \mathrm{CT}$ and TT) genotype groups, with the higher values in the individuals presenting the CT genotype. The medians concentrations of TC $(\mathrm{p}<0.0001)$, HDL-C $(\mathrm{p}=$ $0.0004)$ and LDL-C ( $<$ 0.0001) were significantly different with the higher values in the individuals presenting the TT genotype. Interestingly, these two genotypes (CT and TT) were shown in this study to be associated with T2DM, compared to the CC genotype which was shown to have a protective effect in our population. This confirms that the $\mathrm{T}$ allele for genetic variant not only predisposes for T2DM but could be implicated in the metabolic disorders in the general population. 


\section{Conclusion}

In conclusion, the present study showed that genotype and allele distributions of KLF14 rs4731702 (C/T) gene polymorphism are different between T2DM patients and healthy controls. It also showed for the first time that the KLF14 rs4731702 $(\mathrm{C} / \mathrm{T})$ gene polymorphism is strongly associated with an increased risk of T2DM in this Cameroonian population. In addition, this association is not dependent on a specific phenotype of disease. This candidate genetic variant is a promising target for personalized medicine for the populations of sub-Saharan Africa through the development of clinical genetic testing.

\section{Ethics Approval and Informed Consent}

The National Ethical Review Board of the Cameroon Ministry of Public Health provided an ethical clearance approving the study protocol. Signed informed consent was obtained from all participants after the procedures had been fully explained. The study was carried out according to the guidelines of the Helsinki Declaration.

\section{Data Availability}

All the data created and used to support the findings of this study are included within the article. However, any additional data, to support findings of this study, are available from the corresponding author upon request.

\section{Acknowledgements}

We thank the patients and volunteers who agreed to participate in this study. We are also thankful to all the staff of the National Center for Obesity and the Biotechnology Center for their contribution to the realization of this work.

\section{Funding Statement}

This work has received pre-funding from Professor Eugene Sobngwi \& Professor Wilfred Mbacham pending funding from the African Partnership for Chronic Disease Research strategic award from the UK Medical Research Council under the RC/DFID Concordat agreement (grant number MR/K013491/1).

\section{Authors' Contributions}

Conception and design of experiments: Magellan Guewo-Fokeng, Eugene Sobngwi, Barbara Atogho Tiedeu, Jean-Claude Mbanya and Wilfred F. Mbacham. Clinical data collection and biochemical analysis: Magellan Guewo-Fokeng and Eric Lontchi-Yimagou. Gene amplification, molecular genotyping and statistical analysis: Magellan Guewo-Fokeng and Jean-Paul Chedjou. Data interpretation: Magellan Guewo-Fokeng, Eugene Sobngwi, Barbara Atogho Tiedeu, Jean-Claude Mbanya and Wilfred F. Mbacham. Writing the first draft of the article: Magellan Guewo-Fokeng. Critical discussion and manuscript revision: Magellan Guewo- 
Fokeng, Eugene Sobngwi, Barbara Atogho Tiedeu, Eric Lontchi-Yimagou, JeanClaude Mbanya and Wilfred F. Mbacham. Final editing and approval of the manuscript: Eugene Sobngwi, Barbara Atogho Tiedeu, Jean-Claude Mbanya and Wilfred F. Mbacham. All the authors read and approved the final version of the manuscript.

\section{Conflicts of Interest}

The authors declare no conflicts of interest regarding the publication of this paper.

\section{References}

[1] Guillausseau, P.J., Meas, T., Virally, M., Laloi-Michelin, M., Médeau, V. and Kevorkian, J.P. (2008) Abnormalities in Insulin Secretion in Type 2 Diabetes mellitus. Diabetes \& Metabolism, 34, S43-S48. https://doi.org/10.1016/S1262-3636(08)73394-9

[2] International Diabetes Federation (2019) IDF Diabetes Atlas. 9th Edition, International Diabetes Federation, Brussels. http://www.idf.org/diabetesatlas

[3] McCarthy, M.I. (2010) Genomics, Type 2 Diabetes, and Obesity. New England Journal of Medicine, 363, 2339-2350. https://doi.org/10.1056/NEJMra0906948

[4] Sladek, R., Rocheleau, G., Rung, J., Dina, C., Shen, L., Serre, D., Boutin, P., et al. (2007) A Genome-Wide Association Study Identifies Novel Risk Loci for Type 2 Diabetes. Nature, 445, 881-885. https://doi.org/10.1038/nature05616

[5] Diabetes Genetics Initiative of Broad Institute of Harvard and MIT, Lund University and Novartis Institutes of BioMedical Research (2007) Genome-Wide Association Analysis Identifies Loci for Type 2 Diabetes and Triglyceride Levels. Science, 316, 1331-1336. https://doi.org/10.1126/science.1142358

[6] Wellcome Trust Case Control Consortium (2007) Genome-Wide Association Study of 14,000 Cases of Seven Common Diseases and 3,000 Shared Controls. Nature, 447, 661-678. https://doi.org/10.1038/nature05911

[7] McCarthy, M.I. and Zeggini, E. (2009) Genome-Wide Association Studies in Type 2 Diabetes. Current Diabetes Reports, 9, 164-171. https://doi.org/10.1007/s11892-009-0027-4

[8] Lu, S., Xie, Y., Lin, K., Li, S., Zhou, Y., Ma, P., Lu, Z. and Zhou, X. (2012) Genome-Wide Association Studies-Derived Susceptibility Loci in Type 2 Diabetes: Confirmation in a Chinese Population. Clinical and Investigative Medicine, 35, E327-E333. https://doi.org/10.25011/cim.v35i5.18706

[9] Imamura, M., Takahashi, A., Yamauchi, T., Hara, K., Yasuda, K., Grarup, N., et al. (2016) Genome-Wide Association Studies in the Japanese Population Identify Seven Novel Loci for Type 2 Diabetes. Nature Communication, 7, Article No. 10531. https://doi.org/10.1038/ncomms10531

[10] Rotimi, C.N., Chen, G., Adeyemo, A.A., Furbert-Harris, P., Parish-Gause, D., Zhou, J., Berg, K., et al. (2004) Africa America Diabetes Mellitus (AADM) Study. A Genome-Wide Search for Type 2 Diabetes Susceptibility Genes in West Africans: The Africa America Diabetes Mellitus (AADM) Study. Diabetes, 53, 838-841. https://doi.org/10.2337/diabetes.53.3.838

[11] Chen, G., Adeyemo, A., Zhou, J., Chen, Y., Huang, H., Doumatey, A., et al. (2007) Genome-Wide Search for Susceptibility Genes to Type 2 Diabetes in West Africans: 
Potential Role of C-Peptide. Diabetes Research and Clinical Practice, 78, e1-e6. https://doi.org/10.1016/j.diabres.2007.04.010

[12] Yako, Y.Y., Guewo-Fokeng, M., Balti, E.V., Bouatia-Naji, N., Matsha, T.E., Sobngwi, E., et al. (2016) Genetic Risk of Type 2 Diabetes in Populations of the African Continent: A Systematic Review and Meta-Analyses. Diabetes Research and Clinical Practice, 114, 136-150. https://doi.org/10.1016/j.diabres.2016.01.003

[13] Parker-Katiraee, L., Carson, A.R., Yamada, T., Arnaud, P., Feil, R., Abu-Amero, S.N., et al. (2007) Identification of the Imprinted KLF14 Transcription Factor Undergoing Human-Specific Accelerated Evolution. PLoS Genetics, 3, e65. https://doi.org/10.1371/journal.pgen.0030065

[14] Kerrin, S.S., Asa, K.H., Grundberg, E., Nica, A.C., Thorleifsson, G., Kong, A., et al. (2011) Identification of an Imprinted Master Trans Regulator at the KLF14 Locus Related to Multiple Metabolic Phenotypes. Nature Genetic, 43, 561-564. https://doi.org/10.1038/ng.833

[15] Dang, D.T., Pevsner, J. and Yang, V.W. (2000) The Biology of the Mammalian Kruppel-Like Family of Transcription Factors. The International Journal of Biochemistry \& Cell Biology, 32, 1103-1121. https://doi.org/10.1016/S1357-2725(00)00059-5

[16] Pearson, R., Fleetwood, J., Eaton, S., Crossley, M. and Bao, S. (2008) Kruppel-Like Transcription Factors: A Functional Family. The International Journal of Biochemistry \& Cell Biology, 40, 1996-2001. https://doi.org/10.1016/j.biocel.2007.07.018

[17] Mato-Mofo, E.P., Fosso, P.P., Atogho-Tiedeu, B., Noubiap, J.J., Evehe, M.S., Djokam-Dadjeu, R., et al. (2016) The Pro12Ala Polymorphism in the PPAR- $\gamma 2$ Gene Is Not Associated to Obesity and Type 2 Diabetes in a Cameroonian Population. Journal of BMC Obesity, 3, Article No. 26. https://doi.org/10.1186/s40608-016-0104-6

[18] Nanfa, D., Sobngwi, E., Atogho-Tiedeu B., Noubiap, J.J., Donfack, O.S., Mofo, E.P., et al. (2015) Association between the TCF7L2 rs12255372(G/T) Gene Polymorphism and Type 2 Diabetes Mellitus in a Cameroonian Population: A Pilot Study. Clinical and Translational Medicine, 4, e17. https://doi.org/10.1186/s40169-015-0058-1

[19] Guewo-Fokeng, M., Sobngwi, E., Atogho-Tiedeu, B., Donfack, O.S., Noubiap, J.J., Ngwa, E.N., et al. (2015) Contribution of the TCF7 L2 rs7903146(C/T) Gene Polymorphism to the Susceptibility to Type 2 Diabetes Mellitus in Cameroon. Journal of Diabetes \& Metabolic Disorders, 14, Article No. 26. https://doi.org/10.1186/s40200-015-0148-Z

[20] American Diabetes Association (2012) Diagnosis and Classification of Diabetes Mellitus. Diabetes Care, 35, S64-S71. https://doi.org/10.2337/dc12-s064

[21] World Health Organization (2006) Definition and Diagnosis of Diabetes Mellitus and Intermediate Hyperglycemia. World Health Organization, Geneva.

[22] Matthews, D.R., Hosker, J.P., Rudenski, A.S., Naylor, B.A., Treacher, D.F. and Turner, R.C. (1985) Homeostasis Model Assessment: Insulin Resistance and Beta-Cell Function from Fasting Plasma Glucose and Insulin Concentrations in Man. Diabetologia, 28, 412-419. https://doi.org/10.1007/BF00280883

[23] Guillen, M.A., Mejia, F.A., Villena, J., Turin, C.G., Carcamo, C.P. and Ticse, R. (2015) Insulin Resistance by Homeostasis Model Assessment in HIV-Infected Patients on Highly Active Antiretroviral Therapy: Cross-Sectional Study. Diabetology \& Metabolic Syndrome, 7, Article No. 49.

https://doi.org/10.1186/s13098-015-0046-Z 
[24] Plowe, C.V., Djimde, A., Bouare, M., Doumbo, O. and Wellems T. (1995) Pyrimethamine and Proguanil Resistance-Conferring Mutations in Plasmodium falciparum Dihydrofolate Reductase: Polymerase Chain Reaction Methods for Surveillance in Africa. American Journal of Tropical Medicine and Hygiene, 52, 565-568. https://doi.org/10.4269/ajtmh.1995.52.565

[25] Allain, C.C., Poon, L.S., Chan, C.S., Richmond, W. and Fu P.C. (1974) Enzymatic Determination of Serum Total Cholesterol. Clinical Chemistry, 20, 470-475. https://doi.org/10.1093/clinchem/20.4.470

[26] Bucolo G. and David H. (1973) Quantitative Determination of Serum Triglycerides by Use of Enzymes. Clinical Chemistry, 19, 476-482. https://doi.org/10.1093/clinchem/19.5.476

[27] Burstein, M., Scholnick, H.R. and Morfin R. (1970) Rapid Method for the Isolation of Lipoproteins from Human Serum by Precipitation with Polyanions. Journal of Lipid Research, 11, 583-595. https://doi.org/10.1016/S0022-2275(20)42943-8

[28] Friedewald, W.T., Levy, R.I. and Fredrickson D.S. (1972) Estimation of Low Density Lipoprotein Cholesterol without the Use of the Preparative Ultracentrifuge. Clinical Chemistry, 18, 499-502. https://doi.org/10.1093/clinchem/18.6.499

[29] Expert Panel (2001) Detection, Evaluation, and Treatment of High Blood Cholesterol in Adults. Executive Summary of the Third Report of the National Cholesterol Education Program (NCEP) Expert Panel on Detection, Evaluation, and Treatment of High Blood Cholesterol in Adults (Adult Treatment Panel III). JAMA, 285, 2486 2497. https://doi.org/10.1001/jama.285.19.2486

[30] Gauderman, W.J. and Morrison, J.M. (2006) Quanto: A Computer Program for Power and Sample Size Calculations for Genetic-Epidemiology Studies. https://www.scienceopen.com/document?vid=2944f68a-3b3d-4e86-90a3-3d3c1fab3 ffa

[31] Kong, A., Steinthorsdottir, V., Masson, G., Thorleifsson, G., Sulem, P., Besenbacher, S., et al. (2009) Parental Origin of Sequence Variants Associated with Complex Diseases. Nature, 462, 868-874. https://doi.org/10.1038/nature08625

[32] Huang, P., Yin, R.X., Huang, K.K., Zeng, X.N., Guo, T., Lin, Q.Z., Wu, J., Wu, D.F. and Li, H. and Pan, S.L. (2013) Association of the KLF14 rs4731702 SNP and Serum Lipid Levels in the Guangxi Mulao and Han Populations. BioMed Research International, 2013, Article ID: 231515. https://doi.org/10.1155/2013/231515

[33] Tiedeu, B.A., Guewo-Fokeng, M., Lontchi-Yimagou, E., Mbanya, J.C., Sobngwi, E. and Mbacham, F.W. (2017) Association of rs4731702(C/T) Polymorphism of Krüppel Like Factor 14 (KLF14) Gene with Ketosis-Prone Diabetes (KPD) in a Cameroonian Population. Journal of Global Diabetes \& Clinical Metabolism, 2, Article No. 021.

[34] Gao, K., Wang, J., Li, L., Zhai, Y., Ren, Y., You, H., Wang, B., et al. (2016) Polymorphisms in Four Genes (KCNQ1 rs151290, KLF14 rs972283, GCKR rs780094 and MTNR1B rs10830963) and Their Correlation with Type 2 Diabetes Mellitus in Han Chinese in Henan Province, China. International Journal of Environmental Research and Public Health, 13, Article No. 260. https://doi.org/10.3390/ijerph13030260

[35] Elston, R.C. and Forthofer, R. (1977) Testing for Hardy-Weinberg Equilibrium in Small Samples. Biometrics, 33, 536-542. https://doi.org/10.2307/2529370 